\title{
Clinical experience with the second-generation 3f Enable sutureless aortic valve prosthesis
}

\author{
Thierry Aymard, MD, ${ }^{\mathrm{a}}$ Alexander Kadner, MD, ${ }^{\mathrm{a}}$ Nazan Walpoth, MD, ${ }^{\mathrm{b}}$ Volkhart Göber, MD, ${ }^{\mathrm{a}}$ \\ Lars Englberger, MD, ${ }^{\mathrm{a}}$ Mario Stalder, MD, ${ }^{\mathrm{a}}$ Friedrich Eckstein, MD, ${ }^{\mathrm{a}}$ Claudia Zobrist, $\mathrm{MD},{ }^{\mathrm{c}}$ and \\ Thierry Carrel, $\mathrm{MD}^{\mathrm{a}}$
}

\begin{abstract}
Objective: The 3f Enable aortic bioprosthesis (ATS Medical, Inc, Minneapolis, Minn) represents a new generation of equine pericardial self-expanding valve designed for sutureless implantation. This study evaluated technical aspects of implantation and safety and effectiveness of the valve in the short term. Methods: In an outcome analysis of a consecutive series of 28 patients who underwent aortic valve replacement
for aortic stenosis with the $3 \mathrm{f}$ Enable during an 18 -month period, mean age was $75.7 \pm 6.6$ years, 18 patients were
female $(64.2 \%)$, and mean EuroSCORE was $7.1 \% \pm 1.7 \%$.

Results: Most implanted valves were $23 \mathrm{~mm}$ in diameter (19-27 mm). Mean aortic crossclamp time was $39 \pm 15$ minutes (29-103 minutes), mean cardiopulmonary bypass time was $58 \pm 20$ minutes (41-127 minutes), mean hospital stay was 11 days (7-22 days), and 30-day mortality was 3.5\%. Mean and peak intraoperative transvalvular pressure gradients were $6.1 \pm 2.6$ and $18 \pm 5 \mathrm{~mm} \mathrm{Hg}$, respectively. Trivial and mild paravalvular leaks were observed in 1 patient each. One patient underwent reoperative aortic valve replacement 4 months after initial surgery for severe valve-unrelated paravalvular leakage. Five patients $(18.5 \%)$ required permanent pacemakers. No patients were unavailable for follow-up. One-year survival was $86.2 \%$.
\end{abstract}

Conclusions: The 3-f Enable aortic bioprosthesis can be implanted safely with favorable early hemodynamics. The self-expanding stent allows sutureless implantation with a large valve area. The procedure was fast, although not as fast as expected. This experience has led to continued design and procedural enhancements to facilitate and accelerate future implantation. (J Thorac Cardiovasc Surg 2010;140:313-6)

Aortic valve replacement (AVR) with cardiopulmonary bypass $(\mathrm{CPB})$ is still the treatment of choice for symptomatic aortic stenosis. ${ }^{1}$ The procedure can be performed with an acceptable operative risk, and long-term results are excellent in terms of quality of life and survival.

The concept of the sutureless valve was initially tested in the early $1060 \mathrm{~s},{ }^{2}$ with the idea being to facilitate implantation and shorten ischemic and perfusion times. The concept was abandoned, however, because of multiple complications, such as paravalvular leakage and valve-related thromboembolic events. Recently, sutureless aortic valve implantation has received increasing interest because of the rapid development of transcatheter valve technology. Shortening the time required for AVR could help to reduce the morbidity and mortality, especially for patients who require complex multivalve or combined valve and coronary

\footnotetext{
From the Department of Cardiovascular Surgery, ${ }^{\mathrm{a}}$ the Department of Cardiology, ${ }^{\mathrm{b}}$ and the Institute of Anesthesiology, ${ }^{\mathrm{c}}$ University Hospital Berne, Berne, Switzerland. Disclosures: T. Carrel reports lecture fees from ATS and Edwards.

3f Enable is manufactured by ATS Medical, Inc, Minneapolis, Minn.

Received for publication Aug 13, 2009; revisions received Sept 24, 2009; accepted for publication Oct 15, 2009.

Address for reprints: Thierry Carrel, MD, Professor and Chairman, Department of Cardiovascular Surgery, University Hospital Berne, CH-3010 Berne, Switzerland

(E-mail: thierry.carrel@insel.ch).

$0022-5223 / \$ 36.00$

Copyright (C) 2010 by The American Association for Thoracic Surgery

doi:10.1016/j.jtcvs.2009.10.041
}

procedures. The clinical results reported for the first-generation $3 \mathrm{f}$ Enable sutureless aortic valve prosthesis (ATS Medical, Inc, Minneapolis, Minn) demonstrated feasibility; however, a high percentage of significant paravalvular leakage necessitated device modifications. ${ }^{3}$ The aim of this study was to evaluate the second-generation valve regarding its technical aspects of implantation and its safety and effectiveness in terms of immediate and short-term clinical and hemodynamic results.

\section{MATERIALS AND METHODS Patients}

The study design was a prospective, nonrandomized, open-label pivotal trial designed to evaluate the safety and efficacy of the device with a common clinical investigation plan. Twenty-eight patients who were enrolled at our institution during an 18-month period underwent AVR with the secondgeneration $3 \mathrm{f}$ Enable sutureless aortic valve prosthesis (model $60003 \mathrm{f} \mathrm{En-}$ able; ATS Medical). Patient selection for this type of investigational device was left to the discretion of the surgeon. Patients received an extensive informational paper describing the new prosthesis, the technology of self-expansion, and the necessity for close follow-up.

Ten patients were male and 18 were female $(64.2 \%)$. Mean age was 75.7 \pm 6.6 years (range, $72-89$ years). Mean preoperative pressure gradient was $44 \pm 17 \mathrm{~mm} \mathrm{Hg}$ (range, 35-80 $\mathrm{mm} \mathrm{Hg}$ ), and mean aortic valve area was 0.6 $\pm 0.2 \mathrm{~cm}^{2}$. Mean EuroSCORE was $7.1 \% \pm 1.75 \%$. All patients were in New York Heart Association functional class III or IV.

Postoperative anticoagulation consisted of acetylsalicylic acid (100 mg). Oral anticoagulation was administered only in the presence of any additional risk factor (atrial fibrillation, ejection fraction $<30 \%$ ). Follow-up 


\section{Abbreviations and Acronyms \\ $\mathrm{AVR}=$ aortic valve replacement \\ $\mathrm{CPB}=$ cardiopulmonary bypass}

consisted of both clinical examinations and intraoperative and postoperative echocardiography (at discharge and at 6 and 12 postoperative months). Main exclusion criteria were as follows: patients with previous cardiac surgery, dilated $(>4 \mathrm{~cm})$ and severely calcified ascending aorta and aortic root, and active endocarditis. Combined AVR and myocardial revascularization was not an exclusion criterion. Discordance between the sinotubular ridge and diameter of the aortic annulus is not of concern for this type of valve, because fixation occurs only at the level of the annulus.

The study was approved by the institutional review board of Berne University Hospital. All patients gave written, informed consent.

\section{Description of Implant}

The second generation of the $3 \mathrm{f}$ Enable sutureless aortic valve prosthesis (Figure 1) is available from size $19 \mathrm{~mm}$ to $29 \mathrm{~mm}$ and consists of the following: (1) a self-expanding nitinol stent covered with polyester on the inflow aspect; (2) a 3f aortic bioprosthesis (model 1000; ATS Medical) assembled from 3 equal sections of equine pericardial material crosslinked with formulations of low-concentration glutaraldehyde under specific parameters of time, $\mathrm{pH}$, and temperature (this fixation process is aimed at preserving the collagen architecture of the pericardial material, minimizing the immunogenic potential of the xenogeneic tissue, preserving its flexibility and strength, and optimizing its durability for the intended use); and (3) a polyester flange that conforms to the aortic annulus of the patient (the flange is 2 $\mathrm{mm}$ in thickness and should be positioned approximately within the annulus, covering the removed leaflet remnants). The pliable nitinol stent allows crimping of the valve at low temperatures (about $5^{\circ} \mathrm{C}$; Figure 2). The stent regains its original shape at room temperature because of the memory effect of the nitinol. The sizer is the true size ATS sizer also available for the model $10003 \mathrm{f}$ stentless bioprosthesis.

\section{Implantation Technique}

Surgery was performed through a full sternotomy $(\mathrm{n}=22)$ or ministernotomy $(n=6)$. Standard CPB was established by cannulation of the ascending aorta and the right atrium. Myocardial protection was achieved with $100 \mathrm{~mL}$ antegrade crystalloid single-shot cardioplegia (Cardioplexol; Bichsel Laboratory, Interlaken, Switzerland). Transverse aortotomy was performed approximately $2 \mathrm{~cm}$ above the commissures. The valve was excised, and the annulus was decalcified as for conventional AVR.

Sizing of the prosthesis is a crucial step. Neither oversizing nor undersizing is desirable, because the sizes of the device are really true sizes and it is not possible to expand an oversized Enable valve in a smaller annulus. After the usual rinsing, the valve was immersed in ice slurry to allow the folding and insertion of the stented valve into the applicator (Figure 3). A guiding stitch was placed at the level of the lowest point of the native annulus in one of the intracommissural trigones (preferably at the left noncoronary commissure) to avoid rotation or too-deep insertion of the valve. The stitch was passed through the suture ring of the valve, and the prosthesis was pushed out of the applicator. Expansion of the nitinol stented valve was performed with warm saline solution under constant observation. The tabs were not sutured to the aortic wall but attached to the stent; they came into contact with the aortic wall after expansion of the valve. Inspection of the coronary ostia was easy because of the intra-annular position of the valve. The aortotomy was closed with a running suture, and the operation was terminated in the usual way (Figure 4). Position and function of the valve were assessed by intraoperative transesophageal echocardiography immediately after weaning from $\mathrm{CPB}$.

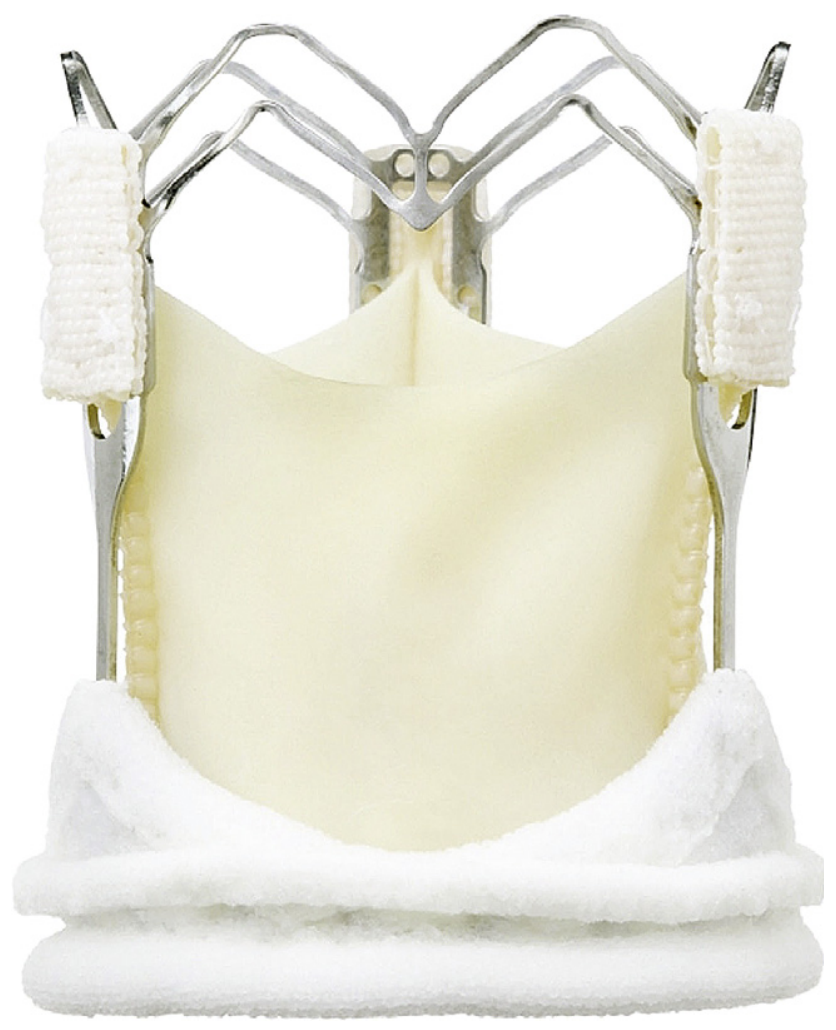

FIGURE 1. Self-expandable 3f Enable aortic valve prosthesis.

Primary end points were perioperative mortality and morbidity, including all events within 30 days. Follow-up was complete at 6 and 12 months.

\section{Statistical Methods}

Common descriptive statistical methods were used. Continuous variables are summarized as mean $\pm \mathrm{SD}$ when normally distributed and as median with absolute or interquartile range when asymmetrically distributed. Categoric variables are presented as numbers with percentages. No comparative statistical analysis was performed.

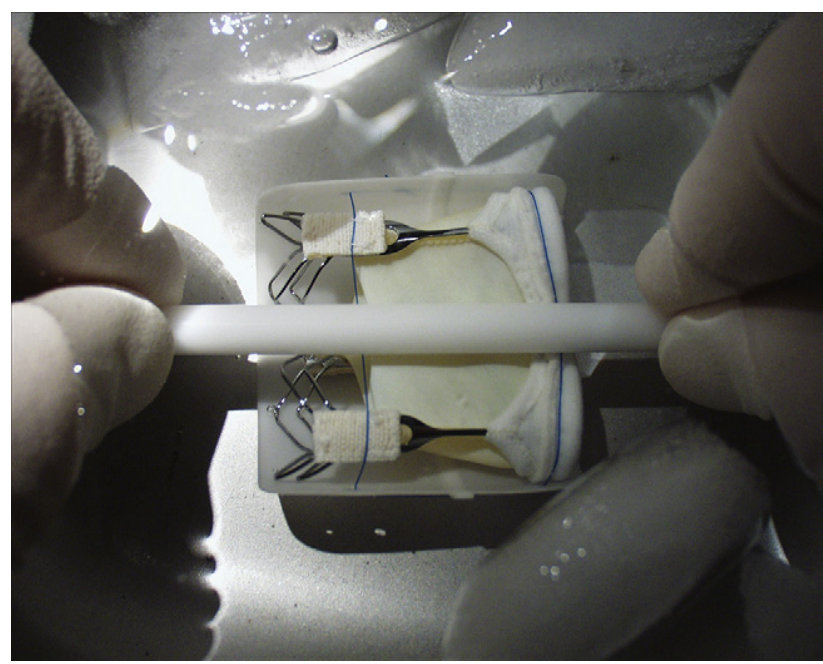

FIGURE 2. Valve folded in iced solution. 


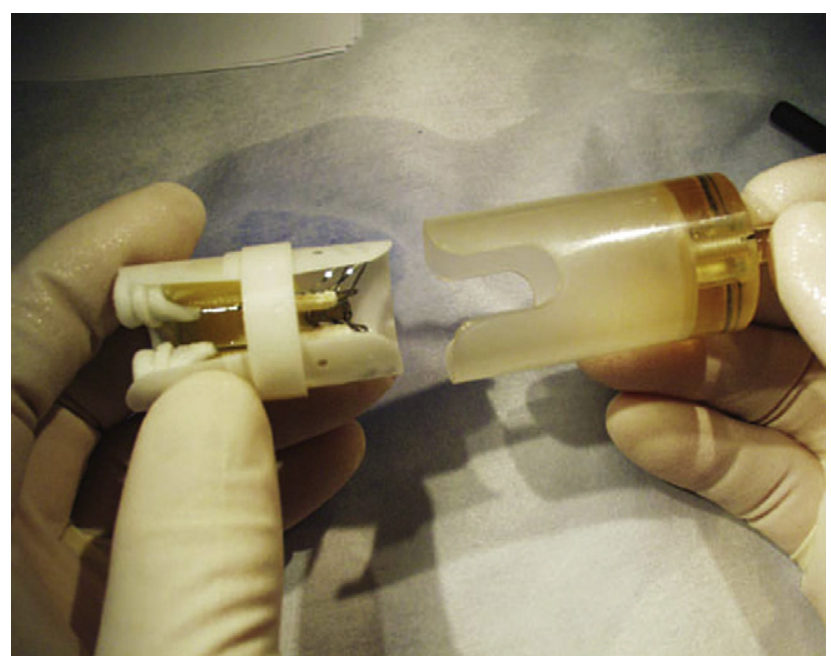

FIGURE 3. Folded valve introduced in release tool.

\section{RESULTS}

Valve implantation was successful at the first attempt in 25 cases. Twenty-seven patients ultimately received an Enable valve. In 1 case the valve was too small, probably because of inappropriate sizing, and it was exchanged for a stented pericardial tissue valve. In 2 cases the valve was removed immediately after deployment and replaced with another Enable prosthesis a size smaller (21 vs $23 \mathrm{~mm}$ ). Prosthesis size ranged from 19 to $27 \mathrm{~mm}$ (median size 23 $\mathrm{mm}$ ). The mean deployment time was $9 \pm 11$ minutes (range, 3-25 minutes). Redeployment for less than perfect alignment with the native valve annulus was necessary in 4 cases. Mean procedural time was $135 \pm 70$ minutes (range, 85-220 minutes), mean CPB time was $58 \pm 20$ minutes (range, 41-127 minutes), and mean crossclamp time was $39.8 \pm 5$ minutes (range, 29-103 minutes). There were no intraoperative deaths or complications. Median hospital stay was 11 days (range, 7-22 days).

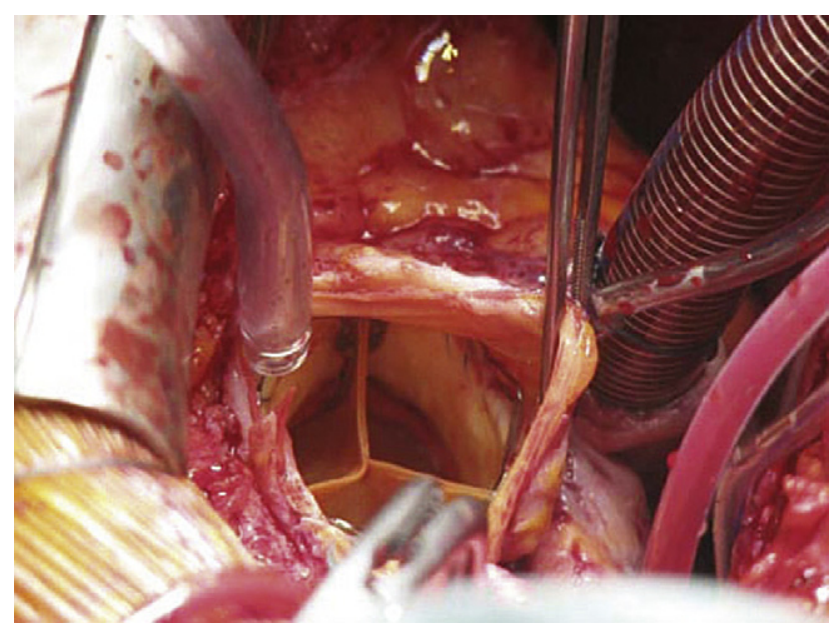

FIGURE 4. Valve in place, just before closure of aortotomy.

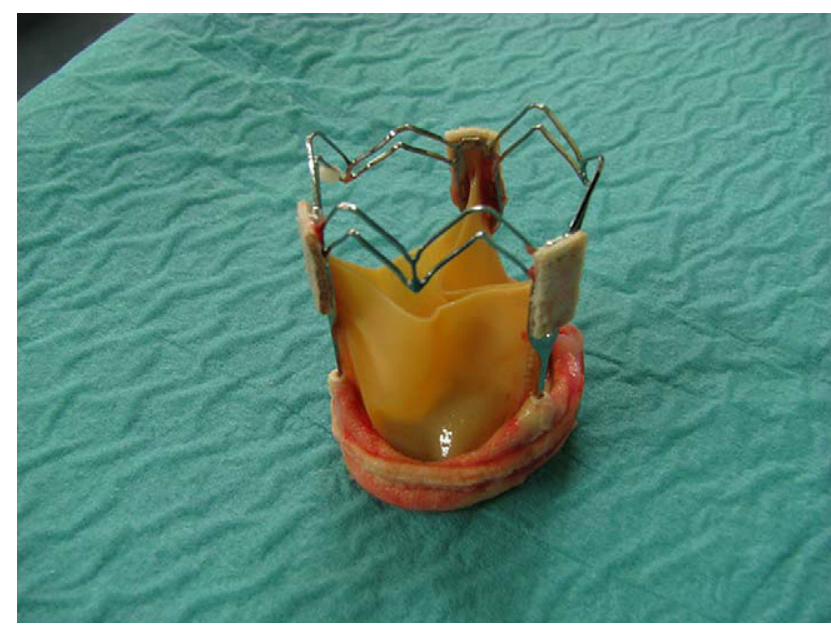

FIGURE 5. Explanted valve.

Follow-up is complete to 18 months. The 30 -day in-hospital mortality was 7\% (1 patient died of intractable ventricular fibrillation on postoperative day 2 and another died of intracerebral hemorrhage on day 7). There were 2 additional deaths during the follow-up period: 1 patient died of gastric cancer at 3 months and 1 died of terminal heart failure at 7 months. All incidents were considered nonvalve related by the physician and an independent Data Safety Management Board (DSMB).

Echocardiographic appearance of the Enable valve was similar - except for visualization of the stent - to the echocardiographic signature of the normal 3-f stentless valve and was characterized by an impressively large coaptation surface. Intraoperative aortic valve area was increased significantly relative to preoperative values $\left(2.1 \pm 0.6 \mathrm{~cm}^{2}\right.$ vs $0.6 \pm$ $0.2 \mathrm{~cm}^{2}, P<.002$ ), and mean pressure gradient decreased significantly from a preoperative value of $44 \pm 17 \mathrm{~mm} \mathrm{Hg}$ to $10.4 \pm 4.1 \mathrm{~mm} \mathrm{Hg}$ at 6 postoperative months $(P<.002)$.

During follow-up, the mean pressure gradient remained stable relative to the intraoperative value $(10 \pm 4 \mathrm{~mm} \mathrm{Hg}$ at 6 months, $11 \pm 2 \mathrm{~mm} \mathrm{Hg}$ at 12 months). Similarly, the aortic valve area remained unchanged from the intraoperative finding $\left(2.0 \pm 0.4 \mathrm{~cm}^{2}\right.$ at 6 months, $2.1 \pm 0.4 \mathrm{~cm}^{2}$ at 12 months). Paravalvular leakage occurred in 3 patients. Two patients had trivial and mild leakage without hemolysis and have not required any treatment as of last follow-up. One patient had significant leakage after 3 months. One month later, the Enable valve was replaced with a biologic stented valve. Explantation of the valve was easy, and the valve was intact (Figure 5). The reason for leakage was not related to the valve. A localized detachment of the anterior mitral valve leaflet was found to be related to deep decalcification of the native aortic annulus.

Permanent pacemaker placement was necessary in 5 cases $(18.5 \%)$. Three patients required pacemaker implantation within the first 12 days, and the other 2 patients received the pacemaker within 30 days. 


\section{DISCUSSION}

The $3 \mathrm{f}$ Enable sutureless aortic stented valve bioprosthesis represents an innovative approach for surgical AVR. ${ }^{3-5}$ As transcatheter valve technology has developed rapidly in the last few years, the devices for surgical AVR have also improved. The theoretic advantages of the new $3 \mathrm{~F}$ Enable prosthesis are the large valve orifice area, comparable to that of a stentless valve (the nitinol stent is only $1 \mathrm{~mm}$ thick), and the potential for fast implantation and subsequently shorter CPB time. The latter is advantageous for all patients, regardless of risk profile. A limited experience with this new prosthesis has been reported by only 2 groups. ${ }^{4,5}$

Because of issues with significant paravalvular leakage, the first-generation device was modified by adding a second ring of polyester clothing at the inflow part of the valve. ${ }^{3}$ On follow-up echocardiography, 2 patients had trivial and mild paravalvular leakage (1 each), which have remained stable during an 18-month follow-up and did not necessitate either surgical intervention or transfusion of red blood cells. Overall hemodynamic performance of the valve was satisfying, with peak gradients similar to those observed with stentless model of the $3 \mathrm{f}$ valve (model 1000) ${ }^{6}$ The aortic valve area was similar to that of stentless valves of the same size (mean $2.1 \pm 0.6 \mathrm{~cm}^{2}$, stable at 1 year). ${ }^{7}$ Because of the small patient cohort within the study that was predominantly smaller-sized valves, a superior hemodynamic profile relative to stentless valves could not be shown.

The reduced time needed for implantation is a theoretic potential advantage of this new type of valve. In our hands, the mean crossclamp time was slightly but not significantly shorter than that needed for stentless valve implantation (39 \pm 15 minutes vs 42 minutes for the Sorin Freedom Solo stentless valve [Sorin SpA, Milan, Italy]). ${ }^{7}$ All manipulations with the Enable valve (crimping, insertion into the applicator, and careful deployment) were part of a learning process with a short learning curve. The main emphasis in this pilot trial was therefore not on the time required for implantation. Additional time might be saved by having the assisting surgeon perform the loading of the device; however, this was not allowed by the protocol of the trial.

No intraoperative complications-such as valve migration, coronary ostia obstruction, mitral regurgitation, or injury to the ascending aorta-occurred in this series. Three patients were found to have paravalvular leakage because of insufficient valve expansion. In 2 cases the valve implanted was too large and the nitinol stent could not fully expand; in these cases, the next smaller valve was implanted without difficulty. In the other case, the surgeon decided to proceed with a stented bioprosthesis.

Relative to the series of Martens and colleagues, ${ }^{5}$ we observed a higher rate of pacemaker implantation $(18.5 \%)$.
We may possibly attribute this phenomenon at our center to the precondition of the patient and valve placement within the annulus where there was radial force exerted on the Hiss bundle at the level of the membranous septum. The need for permanent pacemaker at our center seems to be similar to that observed following transcatheter valve implantation. The rate observed in the more broad patient cohort within the overall multicenter study appears to be in the single-digit percentage rate. Generally speaking, the mortality and morbidity were slightly higher among these 28 patients than among 270 comparable patients (same mean age, original pathology, average EuroSCORE) who underwent isolated or combined AVR during the same period (mortality, 2.2\%; pacemaker implantation, 3.1\%) in our institution. ${ }^{8}$

In conclusion, the second generation of $3 \mathrm{f}$ Enable sutureless valve technology allows favorable clinical and hemodynamic results. The valve has some similarities to devices available for transcatheter valve implantation; the main difference is that the diseased valve can be removed and the annulus decalcified. This allows implantation of a larger valve. Some time saving may be expected after a short learning curve of about 10 deployments. This advantage could prove of major interest for higher risk patients scheduled for more complex procedures (multivalve or valve and coronary surgery). ${ }^{8}$ The experience from this study has lead to continued efforts to enhance the Enable sutureless valve. The next generation should incorporate more comfortable positioning and quicker deployment. We hope to be able to show further reduction of paravalvular leakage and less pacemaker implantation with the new designs.

\section{References}

1. Kvidal P, Bergström R, Hörte LG, Ståhle SR. Observed and relative survival after aortic valve replacement. J Am Coll Cardiol. 2000;35:747-56.

2. Magovern GJ, Cromie HW. Sutureless prosthetic heart valves. J Thorac Cardiovasc Surg. 1963;46:726-36.

3. Leyh R, Yildirim C, Buck T, Sommer S, Herold U, Jakob H. [Early single-center experience with the 3F-Enable aortic valve bioprosthesis]. Herz. 2006;31:423-8. German.

4. Wendt D, Thielmann W, Buck T, Jánosi RA, Bossert T, Pizanis N, et al. First clinical experience and 1-year follow-up with the sutureless 3F-Enable aortic valve prosthesis. Eur J Cardiothorac Surg. 2008;33:542-7.

5. Martens S, Ploss A, Sirat S, Miskovic A, Moritz A, Doss M. Sutureless aortic valve replacement with the 3 f Enable aortic bioprosthesis. Ann Thorac Surg. 2009;87: 1914-8.

6. Linneweber J, Kossagk C, Rogge ML, Dushe S, Dohmen P, Konertz W. Clinical experience with the $3 \mathrm{~F}$ stentless aortic bioprosthesis: one-year follow up. $J$ Heart Valve Dis. 2006;545-8.

7. Aymard T, Eckstein F, Englberger L, Stalder M, Kadner A, Carrel T. The Sorin Freedom SOLO stentless aortic valve: Technique of implantation and operative results in 109 patients. J Thorac Cardiovasc Surg. 2009. Epub 2009 Oct 7.

8. Bloomstein LZ, Gielchinsky I, Bernstein AD, Parsonnet V, Saunders C, Karanam R, et al. Aortic valve replacement in geriatric patients: determinants of in-hospital mortality. Ann Thorac Surg. 2001;71:597-600. 